Acta Crystallographica Section D

Biological

Crystallography

ISSN 0907-4449

\section{J. A. Hinks, ${ }^{\text {a M. Roe, }}{ }^{a}$ J. C. Y. Ho, ${ }^{b}$ F. Z. Watts, ${ }^{b}$ J. Phelan, ${ }^{c}$ M. McAllister ${ }^{c}$ and L. H. Pearl ${ }^{\mathrm{a} *}$}

${ }^{a}$ CR-UK DNA Repair Enzyme Group, Institute of Cancer Research, 237 Fulham Road, South Kensington, London SW3 6JB, England,

${ }^{\mathbf{b}}$ Biochemistry Department, School of Biological Sciences, University of Sussex, Falmer, Brighton, East Sussex BN1 9QG, England, and ${ }^{\mathrm{C} C e n t r e}$ for Structural Biology, Birkbeck College, Malet Street, London WC1E, England

Correspondence e-mail: I.pearl@icr.ac.uk
C 2003 International Union of Crystallography Printed in Denmark - all rights reserved

\title{
Expression, purification and preliminary X-ray analysis of the BRCT domain from Rhp9/Crb2
}

The BRCT domain from Rhp9 (a Schizosaccharomyces pombe DNAdamage checkpoint protein) has been expressed, purified and crystallized. Overexpression in bacterial cells was achieved by minimizing aeration during host cell growth. A robotic screen was used to determine the solubility parameters; concentration of the protein was achieved by exploiting this information. Single crystals suitable for X-ray analysis were obtained in two forms by vapour diffusion (trigonal, unit-cell parameters $a=b=228.04, c=70.42 \AA$, and tetragonal, $P 4 / m$ Laue group symmetry, unit-cell parameters $a=b=72.3, c=91.1 \AA$ ).

\section{Introduction}

Inherited mutations in the BRCA1 gene predispose women to breast and ovarian cancers. BRCA1 encodes a tumour suppressor, BRCA1 (Miki et al., 1994), implicated in DNA repair, cell-cycle checkpoint control and RNA transcription (Deng \& Brodie, 2000; Scully \& Livingston, 2000). The BRCA1 protein comprises two distinct regions: an N-terminal RING motif and a C-terminal BRCT (BRCA1 C-terminal) motif. The C-terminal motif contains two copies of the approximately 90-100-residue sequence known as a BRCT repeat (Koonin et al., 1996; Callebaut \& Mornon, 1997). The two repeats occur in tandem with a short intervening sequence and together this arrangement is termed a BRCT domain. A BRCT superfamily comprising over 40 eukaryotic proteins containing the BRCT repeat sequence has been described (Bork et al., 1997; Huyton et al., 2000). BRCT repeat sequences occur singly, multiply or in tandem pairs as in a BRCT domain such as that of BRCA1. No precise biological function is known, although BRCT repeats are prevalent in proteins concerned with DNA repair or cellcycle control. Both the budding yeast checkpoint protein RAD9 and its homologue in fission yeast Rhp9 have a BRCT domain comprising a tandem pair of C-terminal BRCT repeats. The Rhp9 (Crb2) gene was cloned by complementation of the phenotype of the MMS-sensitive mutant mms-64 (rhp-64) (Willson et al., 1997). The mutation (C664S) was located within the linker region between the two C-terminal BRCT repeats (Ho, 2001). Here, we describe the cloning, expression, preparation and crystallization of this C-terminal region from Rhp9 as an initial step towards the structural solution of the Rhp9 BRCT domain (Rhp9_BRCT). In particular, we explain how problems of low yield and poor solubility were overcome in order to obtain sufficient quantities of the soluble concentrated Rhp9 domain for crystallography.

\section{Materials and methods}

\subsection{Preparation of the Rhp9 BRCT domain (Rhp9_BRCT)}

The sequence encoding the BRCT domain (BRCT 1+2 Rhp9) was amplified by PCR from $S$. pombe (primer 1, 5'-AGAACCATGGATACAGCTCATCTTTGACG-3'; primer 2, 5' AAACCGAATTCAAGTAGAAATATCAGACTG- $3^{\prime}$ ) and inserted as an $N c o I / E c o$ RI fragment into the pRsetB expression vector (Invitrogen). The polylinker region between the His tag and the start of the gene was excized using the flanking NheI and NcoI sites.

The Rhp9 BRCT domain was expressed as a single soluble His-tagged polypeptide (referred to here as Rhp9_BRCT) in Escherichia coli FB810 (DE3) cells. Cells were cultured overnight at $310 \mathrm{~K}$ on LB agar plates supplemented with $100 \mu \mathrm{g} \mathrm{ml}^{-1}$ ampicillin. Several fresh colonies were used to inoculate a $100 \mathrm{ml} \mathrm{LB}$ starter culture, also containing ampicillin. The starter culture was incubated overnight at $310 \mathrm{~K}$ with shaking and aeration. A 11 main culture of LB supplemented with ampicillin and contained within a 21 flask (to minimize aeration) was inoculated with $10 \mathrm{ml}$ of starter culture. The main culture was incubated with shaking at $310 \mathrm{~K}$ until the cell culture reached an optical density measured at $600 \mathrm{~nm}$ of between 0.6 and 0.8. Expression was then induced by addition of IPTG to a final concentration of $0.1 \mathrm{~m} M$ and the incubation temperature was reduced to $303 \mathrm{~K}$. Incubation was continued for a further 3-4 h, when cells were harvested by centrifugation at $4000 \mathrm{~g}$ for 
$15 \mathrm{~min}$. The cell pellet was resuspended in $30 \mathrm{ml}$ of ice-cold buffer $A$ (Tris- $\mathrm{HCl} \mathrm{pH} \mathrm{7,}$ $500 \mathrm{~m} M \mathrm{NaCl}$ plus 'Complete' EDTA-free protease-inhibitor cocktail from Boehringer Mannheim) and stored at $193 \mathrm{~K}$ pending further preparation. Cell pellets were thawed and lysed by sonication on ice using $4 \times 30 \mathrm{~s}$ bursts at full power with cooling between bursts to complete disruption of the cells. The lysate was clarified by centrifugation at $48500 \mathrm{~g}$ for $1 \mathrm{~h}$, then loaded at $2 \mathrm{ml} \mathrm{min}{ }^{-1}$ onto a Pharmacia XK16 column containing $10 \mathrm{ml} \mathrm{Ni}$-NTA resin (Qiagen) previously equilibrated with buffer $A$. The column was washed to a stable baseline with buffer $A$ and then washed for a further 10 column volumes using a step gradient of $95 \%$ buffer $A$ and $5 \%$ buffer $B$ (as buffer $A$ plus $1 M$ imidazole).

The bound protein was eluted in 10 column volumes of $30 \%$ buffer $B$ and collected in $5 \mathrm{ml}$ fractions. Prior to elution, $25 \mu \mathrm{l}$ aliquots of $1 M$ EDTA and $1 M$ DTT plus $500 \mu \mathrm{l}$ aliquots of $5 \mathrm{M} \mathrm{NaCl}$ were dispensed into each collection tube, so that the final EDTA, DTT and $\mathrm{NaCl}$ concentrations in each fraction collected were $5 \mathrm{mM}$, $5 \mathrm{~m} M$ and $1 M$, respectively. Peak fractions were identified by SDS-PAGE, pooled and stored at $277 \mathrm{~K}$ prior to size-exclusion chromatography. Protein sample was loaded in $5 \mathrm{ml}$ aliquots onto a Superdex 75 column $\left(V_{t} \simeq 100 \mathrm{ml}\right)$ previously equilibrated in buffer $C$ (Tris- $\mathrm{HCl} \mathrm{pH} 7,1 M \mathrm{NaCl}, 5 \mathrm{mM}$ EDTA, 5 m $M$ DTT plus 'Complete' EDTAfree protease-inhibitors cocktail) and eluant was collected in $2.5 \mathrm{ml}$ fractions. Fractions containing Rhp9_BRCT were identified by SDS-PAGE, pooled and the protein concentration was estimated spectrophotometrically. The sample was confirmed to be the Rhp9 BRCT domain protein by means of mass spectrometry and N-terminal analysis (data not shown). The protein was stored at $277 \mathrm{~K}$ at a concentration of approximately $1 \mathrm{mg} \mathrm{ml}^{-1}$ pending crystallographic analysis.

\subsection{Automated solubility trial}

An automated trial was devised to characterize Rhp9_BRCT solubility using a Douglas Instruments IMPAX (Chayen et al., 1990, 1992, 1994) Crystallization Robot (see http://www.douglas.co.uk/impax.htm) and accompanying $X$-step Optimization software. A pH gradient ranging between 5.84 and 8.67 was dispensed versus an $\mathrm{NaCl}$ gradient ranging between 0 and $1 M$. The $\mathrm{pH}$ range was achieved using $500 \mathrm{~m} M \mathrm{NaH}_{2} \mathrm{PO}_{4}$ $\mathrm{pH} 4.15$ in line 3 and $500 \mathrm{mMNa} \mathrm{NPO}_{4} \mathrm{pH}$ 8.67 in line 4. Protein (Rhp9_BRCT protein at $2.5 \mathrm{mg} \mathrm{ml}^{-1}$ in $20 \mathrm{mM}$ sodium phosphate buffer $\mathrm{pH}$ 8, $300 \mathrm{~m} M \mathrm{NaCl}, 300 \mathrm{~m} M$ imidazole) was loaded in line $1, \mathrm{NaCl}$ stock $(5 M)$ in line 2 and water (distilled, demineralized, ultra-filtered) in line 5. $3 \mu \mathrm{l}$ drops were dispensed into a Nunc HLA 72-well plate containing approximately $12 \mathrm{ml}$ of mineral oil. Protein solubility was assessed by microscopic examination of the drops for signs of precipitation both immediately after dispensing and following incubation at room temperature overnight. Results from this screen were used to determine the eventual Rhp9_BRCT purification and storage buffers for optimal solubility and also influenced the development of a concentration protocol (see §3).

\subsection{Rhp9_BRCT concentration.}

Concentration was achieved by deliberate precipitation using a low-salt buffer $(20 \mathrm{mM}$ Tris $\mathrm{pH} 8$ only) followed by dissolution of the protein pellet in the desired volume of optimal buffer $(50 \mathrm{~m} M$ Tris $\mathrm{pH} 7,1 M$ $\mathrm{NaCl}$ ). In this way, concentrations of up to $20 \mathrm{mg} \mathrm{ml}^{-1}$ were achieved which were sufficient for crystallography. Concentrated protein was clarified by centrifugation followed by either 0.2 or $0.1 \mu \mathrm{m}$ ultrafiltration in preparation for crystal trials. Analysis by dynamic light scattering (data not shown) ensured that it was not aggregated.

\subsection{Crystallization and preliminary $X$-ray analysis of Rhp9_BRCT}

Sparse-matrix Crystal Screens 1 and 2 (Hampton Research; Jancarik \& Kim, 1991; Cudney et al., 1994) were reordered for compatibility with Douglas Instruments ASPRUN software. This involved organizing the solutions into three sections: viscous organic precipitants, non-viscous organic precipitants and inorganic precipitants. The solutions within each section were ordered alphabetically by precipitant, by increasing concentrations and by $\mathrm{pH}$ where a precipitant was used more than once at the same concentration. The salt precipitants were ordered by anion followed by cation. Precise details can be viewed at the websites http:// www.douglas.co.uk/cryscr1.htm and http:// www.douglas.co.uk/cryscr2.htm.

Solutions were dispensed and mixed in a 1:1 ratio with a $15 \mathrm{mg} \mathrm{ml}^{-1}$ solution of Rhp9_BRCT in $50 \mathrm{~m} M$ Tris pH 7, $1 \mathrm{M} \mathrm{NaCl}$ using the Douglas Instruments robot. Drops were delivered into a Nunc HLA 72-well plate (one screen per plate) containing approximately $12 \mathrm{ml}$ of mineral oil; the final volume of each drop was $2 \mu \mathrm{l}$. Duplicate screens were set up at both room tempera- ture and $287 \mathrm{~K}$. Interesting conditions were investigated further by microbatch using the robot's $X$-step Optimization program and also by vapour-diffusion experiments until an optimum condition was established. Excessive nucleation was eliminated by ultrafiltration of the crystal buffer and filtration of the protein solution (Chayen $e t$ al., 1993).

\section{Results and discussion}

\subsection{Preparation of Rhp9 BRCT}

A number of different E. coli strains were screened as hosts during optimization of Rhp9_BRCT expression (data not shown). These small-scale ( $5 \mathrm{ml}$ cultures) expression trials revealed that yields were improved by omitting the pLysS plasmid and by using FB810 (DE3) cells in preference to other strains. Initial attempts to scale up expression from $5 \mathrm{ml}$ to 11 resulted in a severe reduction in Rhp9_BRCT expression levels. Rhp9_BRCT was clearly visible on Coomassie stained gels when prepared from a $5 \mathrm{ml}$ culture, yet Western blotting was required to detect Rhp9_BRCT prepared from a 11 culture. In order to investigate the effect of changes in aeration level on accumulation of soluble Rhp9_BRCT, we performed shake-flask cultures over a range of media volumes (400-1000 ml) in identical (2 1) flasks and under identical culture conditions. Surprisingly, this indicated that over the range of conditions tested, soluble accumulation of Rhp9_BRCT was inversely proportional to aeration level/agitation efficiency (Fig. 1). Higher aeration therefore resulted in lower accumulation of soluble Rhp9_BRCT. Soluble expression was further improved by lowering the incubation temperature to $303 \mathrm{~K}$ (from $310 \mathrm{~K}$ ) during

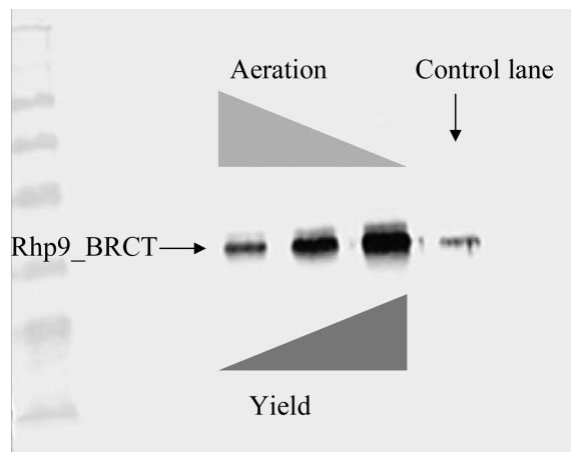

Figure 1

Western blot demonstrating the effect of aeration on Rhp9_BRCT expression. Values for culture volume expressed as a percentage of total flask volume were, from left to right: $30,40,50$, and $20 \%$ (control lane). A value of $50 \%$ (e.g. 11 in a 21 flask) was adopted for large-scale growths. 
induction and by using a lower level of IPTG ( $0.1 \mathrm{~m} M$ rather than $1 \mathrm{~m} M)$. Initially, the lysis and IMAC purification was attempted in a buffer of $50 \mathrm{~m} M$ Tris $\mathrm{pH} 8,100 \mathrm{mM}$ $\mathrm{NaCl}$. However, Rhp9_BRCT did not remain soluble in this buffer once its concentration exceeded $1 \mathrm{mg} \mathrm{ml}^{-1}$ and precipitation occurred immediately on elution from the Ni-NTA column. To reduce precipitation, a $50 \mathrm{~m} M$ phosphate buffer $\mathrm{pH}$ 8 containing $300 \mathrm{mM} \mathrm{NaCl}$ was used for the IMAC step and fractions were collected in tubes containing enough stock EDTA to bring the final concentration in each fraction to $5 \mathrm{~m} M$. This alleviated problems of Rhp9_BRCT precipitation on elution, but storage below room temperature still caused precipitation. At concentrations of approximately $0.5 \mathrm{mg} \mathrm{ml}^{-1}$ a slight precipitate could be observed and concentration beyond $2.5 \mathrm{mg} \mathrm{ml}^{-1}$ could not be achieved using conventional ultrafiltration methods. Further purification by size-exclusion chromatography was also hampered by the

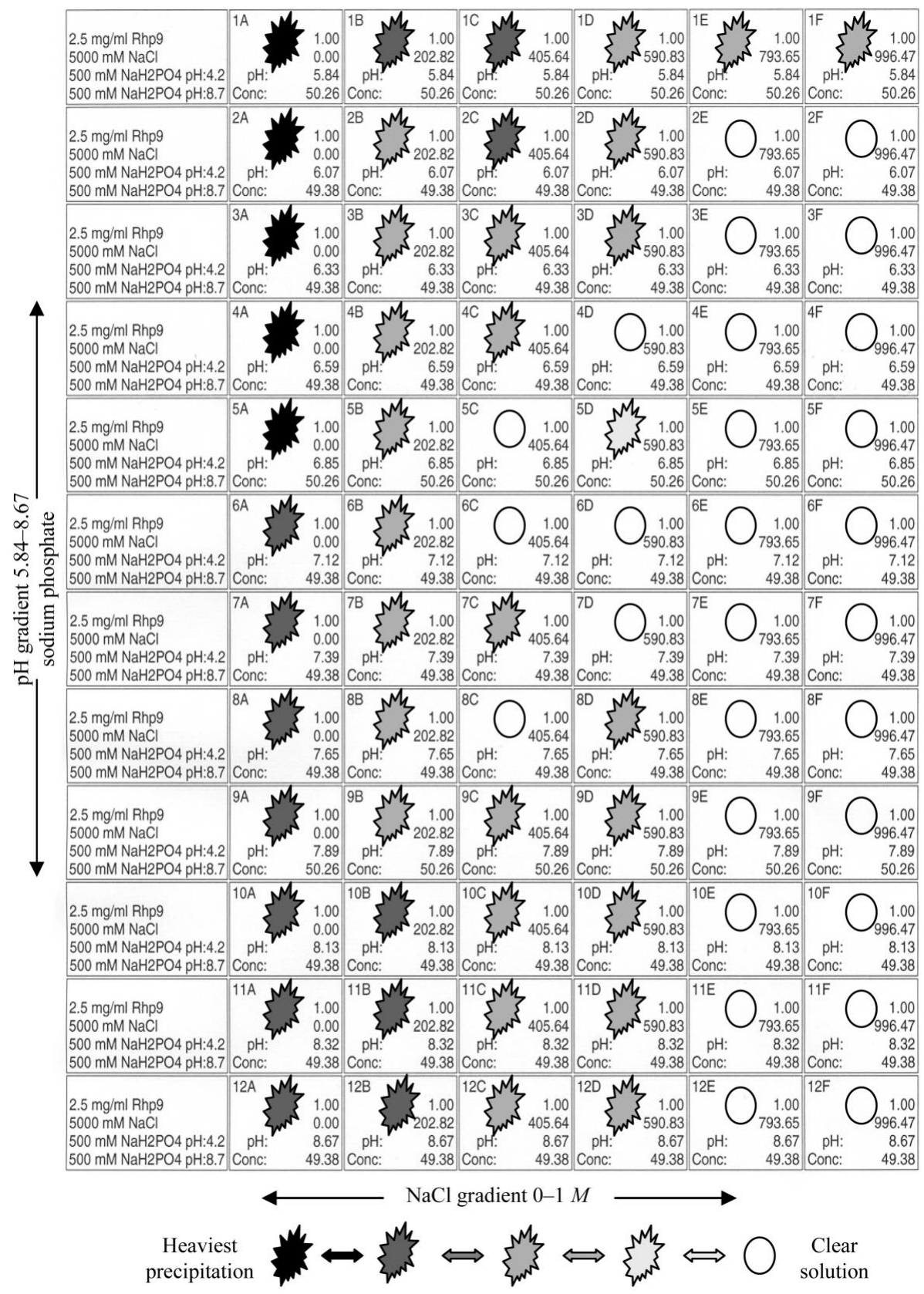

Figure 2

Automated solubility screen dispensed under oil by Douglas Instruments robot into a 72-well microtitre plate. Protein stock concentration was $2.5 \mathrm{mg} \mathrm{ml}^{-1}$, the $\mathrm{pH}$ range was 5.84-8.67 and the $\mathrm{NaCl}$ concentration range was 0-996.5 $\mathrm{m} M$. The $\mathrm{NaCl}$ stock concentration was $5 M$. The final protein concentration was $1.0 \mathrm{mg} \mathrm{ml}^{-1}$ and the final buffer concentration was $50 \mathrm{~m} M$.

tendency of Rhp9_BRCT to precipitate on the column.

\subsection{Automated solubility trial}

At this stage, we devised a screen to investigate Rhp9_BRCT solubility. This used the Douglas Instruments robot to dispense a grid of conditions ranging $\mathrm{pH}$ against $\mathrm{NaCl}$ concentrations at room temperature (Fig. 2). We used the maximum concentration of Rhp9_BRCT then available $\left(2.5 \mathrm{mg} \mathrm{ml}^{-1}\right)$ in the buffer prevailing following the first successful IMAC step (i.e. $50 \mathrm{~m} M$ sodium phosphate $\mathrm{pH} 8,300 \mathrm{mM}$ $\mathrm{NaCl}, \quad 300 \mathrm{~m} M$ imidazole). The results (Fig. 3) demonstrated that Rhp9_BRCT was most soluble at $\mathrm{pH} 7.12$, where it remained in solution at $550 \mathrm{mM} \mathrm{NaCl}$ (plus $150 \mathrm{mM}$ final imidazole). As the $\mathrm{NaCl}$ concentration increased, the Rhp9_BRCT solubility improved and the range of $\mathrm{pH}$ tolerated without precipitation widened. The maximum $\mathrm{pH}$ range ( $\mathrm{pH}$ 6.07-8.67) was achieved at a minimum $\mathrm{NaCl}$ concentration of $950 \mathrm{~m} M$ (plus $150 \mathrm{~m} M$ final imidazole). Following this screen, the buffers used during purification were modified by reverting to Tris (preferable to phosphate for crystallography), reducing the $\mathrm{pH}$ to 7 and increasing the $\mathrm{NaCl}$ concentration used to $500 \mathrm{~m} M$ during IMAC and $1 M$ during size-exclusion chromatography. The routine use of $5 \mathrm{~m} M$ EDTA and $5 \mathrm{~m} M$ DTT downstream of IMAC, plus 'Complete' (EDTAfree) protease-inhibitor cocktail and $0.01 \%$ sodium azide throughout, also helped to

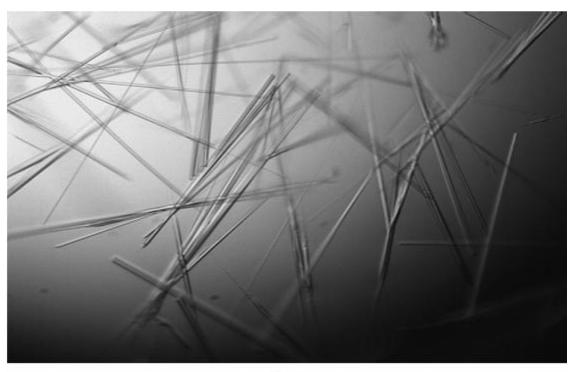

(a)

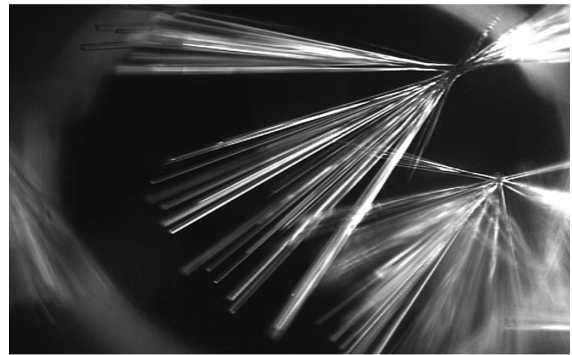

(b)

Figure 3

Micrographs of Rhp9_BRCT crystals grown by vapour diffusion under condition 1 . Approximate dimensions of the crystals are $15 \times 15 \times 800 \mu \mathrm{m}$. 
stabilize the protein during purification and storage at $277 \mathrm{~K}$.

\subsection{Rhp9_BRCT concentration}

Even once optimum conditions for Rhp9_BRCT solubility had been established, the pure protein could not be concentrated beyond $2.5 \mathrm{mg} \mathrm{ml}^{-1}$ by conventional (i.e. ultrafiltration-based) methods. Consequently, we exploited the tendency of Rhp9_BRCT to precipitate in low-salt solution and our ability to redissolve the precipitate in a high-salt solution. This had the advantage of allowing us to select a desired final concentration simply by precipitating a known volume of $1 \mathrm{mg} \mathrm{ml}^{-1}$ Rhp9_BRCT stock and then calculating the required volume of the high-salt solution. Centrifugation and filtration steps followed dissolution to ensure that there were no undissolved aggregations remaining in the final solution which might adversely influence crystal trials, either by inducing unwanted precipitates or by providing an excessive number of nucleation sites. Protein concentrated in this way was analysed by means of dynamic light scattering, confirming that the solution was monodisperse and contained a $36 \mathrm{kDa}$ monomeric protein (data not shown).

\subsection{Crystallization of Rhp9_BRCT}

The sparse-matrix trials revealed two potential conditions; when optimized, both produced crystals suitable for X-ray studies. In each case, the protein was prepared in a solution of $50 \mathrm{~m} M$ Tris $\mathrm{pH} \mathrm{7,1} M \mathrm{NaCl}$.
3.4.1. Condition 1. Straw-like crystals $\sim 15 \times 800 \mu \mathrm{m}$ (Figs. $3 a$ and $3 b$ ) grew at room temperature in $1-2 \mathrm{~d}$ from hanging drops consisting of $50 \%$ protein solution $\left(6 \mathrm{mg} \mathrm{ml}^{-1}\right)$ and $50 \%$ well buffer. Well buffer comprised $100 \mathrm{~m} M$ sodium cacodylate $\mathrm{pH}$ 6.5, 7.26\% PEG 8000 and $200 \mathrm{mM}$ calcium acetate. Crystals diffracted to $4 \AA$ and were found to be in a trigonal space group, most likely $P 3_{2} 21$, with approximately six molecules per asymmetric unit and a solvent content of $60 \%$. Unit-cell parameters were $a=b=228.04, c=70.42 \AA$, $\alpha=\beta=90, \gamma=120^{\circ}$.

3.4.2. Condition 2. Small crystals $\sim 50 \mu \mathrm{m}$ across were grown (not shown) in hanging drops at $287 \mathrm{~K}$ using a well solution consisting of $100 \mathrm{~m} M$ Tris- $\mathrm{HCl} \mathrm{pH} \mathrm{8.5,} \mathrm{2.0} M$ ammonium sulfate and $7 \mathrm{mg} \mathrm{ml}^{-1}$ protein solution. Data were collected to $5 \AA$ and the crystals were found to be tetragonal, probably with $P 4 / m$ Laue group symmetry, and had unit-cell parameters $a=b=72.3$, $c=91.1 \AA$ and one molecule per asymmetric unit. The solvent content was calculated to be $70 \%$.

\section{Summary}

Here, we have described the preparation and crystallization of the Rhp9 BRCT domain. In doing so we have drawn attention to the fact that reduced levels of protein expression may occasionally arise owing to aeration levels which are too high, rather than too low as might intuitively be expected. We have also demonstrated a screen to establish the solubility characteristics of a protein, enabling the optimization of buffer conditions during protein purification.

This work was supported by Cancer Research UK.

\section{References}

Bork, P., Hofmann, K., Bucher, P., Neuwald, A. F., Altschul, S. F. \& Koonin, E. V. (1997). FASEB J. 11, 68-76.

Callebaut, I. \& Mornon, J. P. (1997). FEBS Lett. 400, 25-30.

Chayen, N. E., Radcliffe, J. \& Blow, D. M. (1993). Protein Sci. 2, 113-118.

Chayen, N. E., Shaw Stewart, P. D. \& Baldock, P. (1994). Acta Cryst. D50, 456-458.

Chayen, N. E., Shaw Stewart, P. D. \& Blow, D. M (1992). J. Cryst. Growth, 122, 176-180.

Chayen, N. E., Shaw Stewart, P. D., Maeder, D. L. \& Blow, D. M. (1990). J. Appl. Cryst. 23, $297-$ 302 .

Cudney, R., Patel, S., Weisgraber, K., Newhouse, Y. \& McPherson, A. (1994). Acta Cryst. D50, 414-423.

Deng, C. X. \& Brodie, S. G. (2000). Bioessays, 22 728-737.

Ho, J. C. Y. (2001). DPhil thesis, University of Sussex, England.

Huyton, T., Bates, P. A., Zhang, X., Sternberg, M. J. \& Freemont, P. S. (2000). Mutat. Res. 460, 319 332.

Jancarik, J. \& Kim, S.-H. (1991). J. Appl. Cryst. 24, 409-411.

Koonin, E. V., Altschul, S. F. \& Bork, P. (1996) Nature Genet. 13, 266-268.

Miki, Y. et al. (1994). Science, 266, 66-71.

Scully, R. \& Livingston, D. M. (2000). Nature (London), 408, 429-432.

Willson, J., Wilson, S., Warr, N. \& Watts, F. Z. (1997). Nucleic Acids Res. 25, 2138-2146. 